\title{
Chemiosmosis principle versus murburn concept: Why do cells need oxygen? Deducing the underpinnings of aerobic respiration by mechanistic predictability
}

\author{
Kelath Murali Manoj ${ }^{1 *}$, Vidhu Soman ${ }^{2}$, Vivian David Jacob ${ }^{1}$, Abhinav Parashar ${ }^{3}$, Daniel Andrew \\ Gideon ${ }^{4}$, Manish Kumar ${ }^{1}$, Afsal Manekkathodi ${ }^{5}$, Surjith Ramasamy ${ }^{6}$, Kannan Pakhirajan $^{6}$ \\ ${ }^{* 1}$ Satyamjayatu: The Science \& Ethics Foundation, \\ Snehatheeram, Kulappully, Shoranur-2 (PO), Kerala, India-679122. \\ satyamjayatu@yahoo.com \\ ${ }^{2}$ Department of Biochemical Engineering and Biotechnology, \\ Indian Institute of Technology Delhi, New Delhi, India-110016. \\ ${ }^{3}$ Department of Biotechnology, \\ Vignan's Foundation for Science, Technology \& Research, Vadlamudi, Guntur, India-522213. \\ ${ }^{4}$ Department of Biotechnology \& Bioinformatics, \\ Bishop Heber College (Autonomous), Tennur, Tiruchirappalli, India-620017. \\ ${ }^{5}$ Photovoltaics and Thin-film Solar Cells, \\ Qatar Environment and Energy Research Institute, Hamad Bin Khalifa University, Ar-Rayyan, Qatar. \\ ${ }^{6}$ Department of Biosciences and Bioengineering, \\ Indian Institute of Technology Guwahati, Guwahati, Assam, India-781039.
}

\begin{abstract}
The long-standing explanation for cellular respiration (mitochondrial oxidative phosphorylation, mOxPhos) in textbooks is proton-centric and involves the elements of Rotary ATP synthesis, Chemiosmosis principle, Proton pumps and Electron transport chain (in short, the RCPE model). Addressing certain lacunae in the RCPE model, an alternative scheme based on murburn concept was proposed in 2017 (Manoj, 2017). The new proposal is oxygen-centric in essence, and it advocates constructive roles for diffusible reactive oxygen species (DROS) in electron transfer reactions and ATP-synthesis. By the end of 2018, significant arguments and experimental evidences (in vitro, in situ, and in silico) had accumulated supporting the new mechanism. Herein, the authors compare the predictive capabilities of the two models. Theoretical concepts and expectations are detailed to differentiate the two models, and the correlations are cross-checked with the available data/information. Experimental strategies are further charted to delineate and demarcate the two hypotheses' relevance in mOxPhos.
\end{abstract}

Keywords: cellular/aerobic respiration, mitochondria, ATP synthesis, respiratory complexes, oxidative phosphorylation, murburn concept, chemiosmosis, electron transport chain (ETC), 


\section{The heads and tales of the RCPE and murburn models for oxidative phosphorylation}

The chemiosmosis explanation for cellular respiration was proposed by Peter Mitchell (Mitchell, 1961). He postulated that the protein complexes embedded in the inner mitochondrial membrane pump protons from matrix into the inter-membrane space (IMS). This proton-surplus in the IMS yields a trans-membrane chemical/proton differential or potential (TMP), which drives ATP synthesis in the mitochondrial matrix. When this hypothesis was proposed, not even a shred of evidence existed to support the idea (Prebble, 2001; Prebble and Weber, 2003). However, within a couple of decades, several researchers went on to support this paradigm (Jagendorf and Uribe, 1966; Reid, Moyle and Mitchell, 1966; Junge, Schliephake and Witt, 1968; Liberman, Topaly and Tsofina, 1969; Racker and Stoeckenius, 1974). Particularly in that regard, Paul Boyer hypothesized that the influx of IMS protons into the matrix (through the proton pore of Complex V) serves as an electro-mechanical link between electron transfers (ET) and phosphorylation. Therefore, Complex V is understood to be a rotary ATP synthase (Boyer, 1997). This proton-centric model shall be henceforth referred to as the RCPE model and its salient components/features are depicted in Figure 1. In the Mitchell-Boyer paradigm, diffusible reactive oxygen species (DROS) are unaccounted and considered as wasteful/toxic products. The RCPE working machine model can be compared with a hydroelectric plant (water-mill) or an automobile. The proton-centric scheme fell short to explain the theoretical higher ATP yield mandated by cell metabolic needs and the experimental reports of higher efficiency by several researchers (Lee et al., 1996; Hinkle, 2005). In spite of the recognition accorded to the RCPE model, several leading researchers continued to question the same owing to its inherent incongruities (Williams, 1979; Ling, 1981; Wainio, 1985; Nałęcz, 1986; Slater, 1987; Nath, 2010). Moreover, the fact that mitochondria are practically proton-limited microcosms proved to be this model's Achilles' heel (Manoj, 2017, 2018a).

To overcome such limitations of the chemiosmosis hypothesis, Kelath Murali Manoj (KMM) proposed an evidence-based oxygen-centric explanation for mOxPhos in 2017 (Manoj, 2017). This new understanding was built on experimental insights gained from- (i) KMM's group's works on heme and flavin protein systems (Manoj and Hager, 2001, 2008; Manoj et al., 2010; Manoj, Gade and Mathew, 2010; Andrew, Hager and Manoj, 2011; Gade, Bhattacharya and Manoj, 2012; Parashar and Manoj, 2012; Gideon et al., 2012; Parashar, Gade, et al., 2014; 
Parashar, Venkatachalam, et al., 2014; Manoj, Parashar and Venkatachalam, 2015; Manoj, Venkatachalam and Parashar, 2016; Venkatachalam, Parashar and Manoj, 2016; K.M. Manoj, Parashar, Gade, et al., 2016; K.M. Manoj, Parashar, Venkatachalam, et al., 2016; Kelath Murali Manoj et al., 2016), (ii) newly available structural details of mitochondrial protein complexes (Fiedorczuk et al., 2016; Wu et al., 2016), and (iii) accumulated awareness on cell/mitochondrial physiology (Picard et al., 2011; Zorov, Juhaszova and Sollott, 2014; Sazanov, 2015). For the mOxPhos reaction system, this mechanistic view considers membrane complexes as ADPbinding and oxygen-activating (DROS generating and modulating) agents and protons as a "crucial limiting reactant" (affecting several equilibriums). In the murburn model, DROS serve as the "chemical coupling agent" which directly links NADH oxidation with ATP synthesis (Manoj et al., 2019). Herein, trans-membrane potential (TMP) formation is seen as a consequence of high amounts of negatively charged transient oxygen-centered species formed within the matrix, around the inner mitochondrial membrane. This oxygen-centric model shall be henceforth referred to as murburn model and its elements are shown in Figure 2. A grill/hearth or nuclear reactor is comparable with the murburn model of mOxPhos.
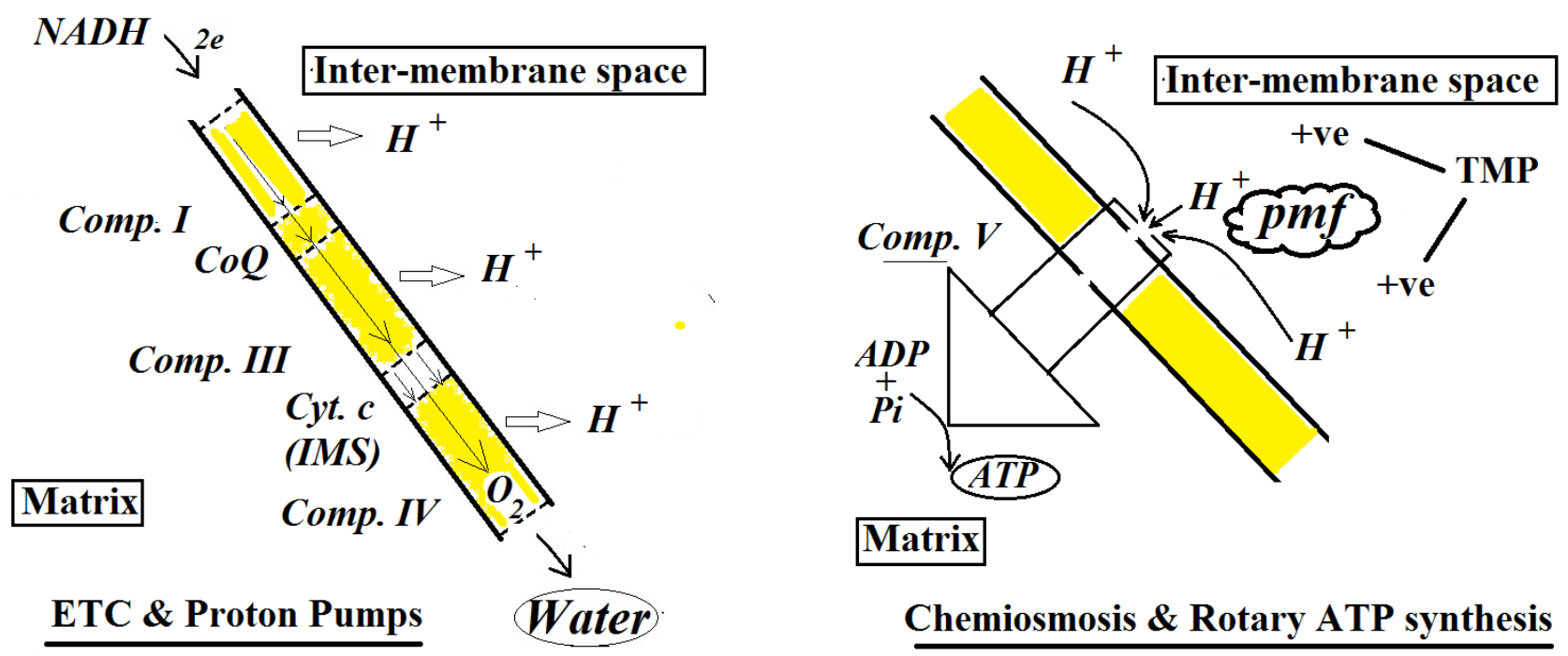

Chemiosmosis \& Rotary ATP synthesis

Figure 1: The RCPE hypothesis has two independent 'deterministic' parts that solicit a staggered operational/regulatory mechanistic sequence. First, a proton differential (set up between the matrix and inter-membrane space, IMS) needs to be generated by the ETC (which also serve as proton pumps) and then the chemiosmotic proton motive force (pmf) or/and transmembrane potential (TMP) are harvested to synthesize ATP through a rotary function of Complex V. Oxygen is needed/reacted only at Comp. IV. 


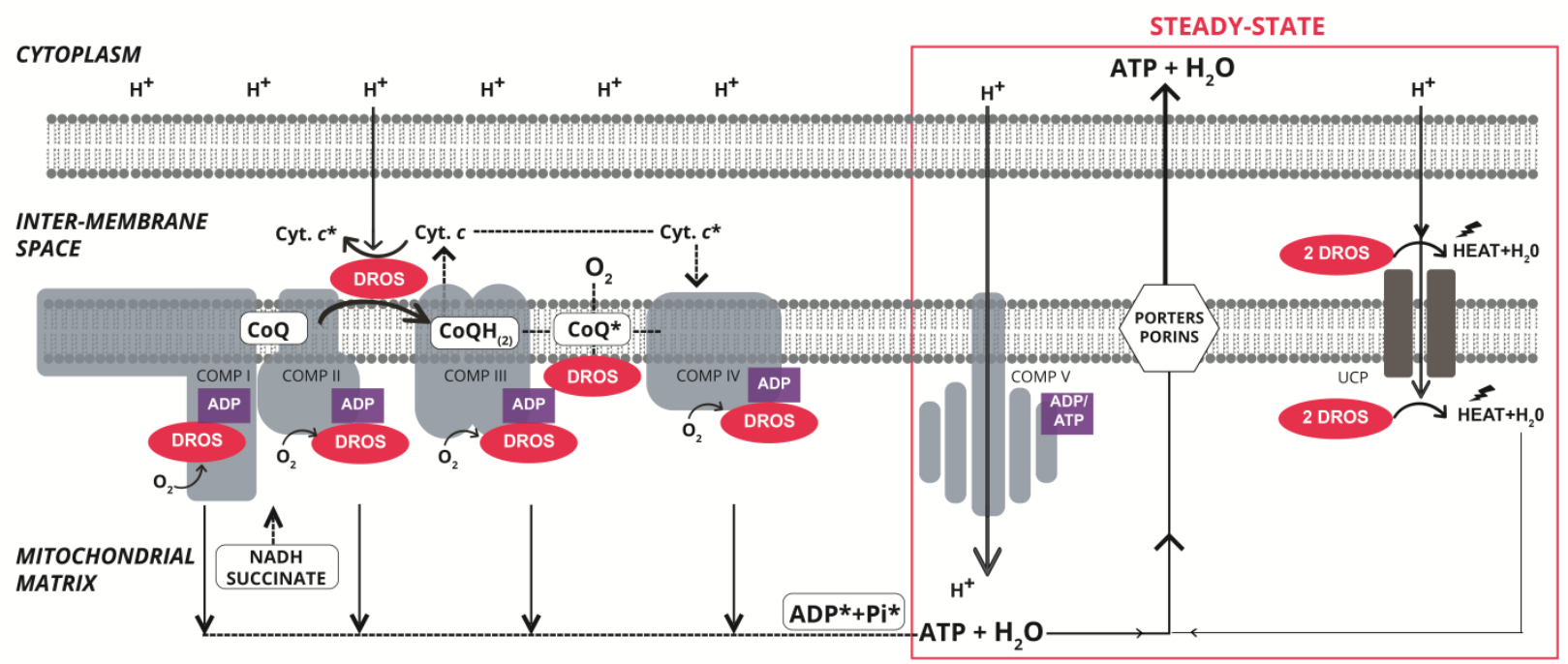

Figure 2: The Murburn scheme involves stochastic interactions and equilibriums, and obligatorily requires oxygen/DROS at several points. DROS is needed as activating or catalytic agents and the whole system works in steady-state, with Complex V serving as a trans-membrane conduit for cytoplasmic protons. The activation of ADP/Pi for the synthesis of ATP occurs at multiple loci.

Table 1 delineates the roles of key components of the two models and the fundamental mechanistic differences between them.

Table 1: Salient mechanistic differences between the physiological models for mOxPhos.

\begin{tabular}{llll}
\hline No. & Facets / Roles & RCPE model & Murburn model \\
\hline $\mathbf{1}$ & $\begin{array}{l}\text { Protein Complexes } \\
\text { (Protons \& proton } \\
\text { pumps })\end{array}$ & $\begin{array}{l}\text { Membrane-proteins network } \\
\text { to form an ETC and also serve } \\
\text { as proton pumps. They } \\
\text { employ copious amounts of } \\
\text { protons as key operative } \\
\text { agents. }\end{array}$ & $\begin{array}{l}\text { Membrane complexes are not proton } \\
\text { pumps but ADP-binders cum DROS } \\
\text { generators (modulators). Protons } \\
\text { influence multiple reaction } \\
\text { equilibriums and kinetics thereof. }\end{array}$ \\
$\mathbf{2}$ & Oxygen/DROS & $\begin{array}{l}\text { Oxygen is the terminal } \\
\text { electron acceptor and DROS } \\
\text { are toxic/waste products. }\end{array}$ & $\begin{array}{l}\text { Oxygen is the key operative agent } \\
\text { required for forming the catalytically } \\
\text { important DROS. }\end{array}$ \\
$\mathbf{3}$ & $\begin{array}{l}\text { Pivotal driving force that } \\
\text { recycles matrix protons and } \\
\text { synthesizes ATP. }\end{array}$ & $\begin{array}{l}\text { Secondary result that aids the inward } \\
\text { movement of cytoplasmic } \\
\text { protons/cations. }\end{array}$ \\
ATP-synthesis in & $\begin{array}{l}\text { Complex V is the sole agent, } \\
\text { which requires only IMS } \\
\text { steady-state }\end{array}$ & $\begin{array}{l}\text { All membrane complexes and } \\
\text { cytoplasmic protons are involved. }\end{array}$ \\
& $\begin{array}{l}\text { Connectivity } \\
\text { between ET and } \\
\text { ATP-synthesis }\end{array}$ & $\begin{array}{l}\text { No direct connection; indirect } \\
\text { electro-mechanical } \\
\text { connectivity via protons. }\end{array}$ & $\begin{array}{l}\text { DROS directly connects ET with } \\
\text { ATP-synthesis via a catalytic } \\
\text { reaction scheme. }\end{array}$ \\
\hline
\end{tabular}




\section{A critical appraisal of the fundamental predictive abilities of the two models}

The mandate of this manuscript is to compare the two models for the predictability of outcomes with respect to the experimental data currently available on the mOxPhos system. With reference to the context of the major mechanistic criteria highlighted in Table 1, a critical discussion is presented in a tabular form within Table 2. Furthermore, the citations to the information listed therein can be available from KMM's recent published works (Manoj, 2018a, 2018b; Manoj, Gideon and Jacob, 2018; Manoj et al., 2019). Other information perused herein are supported by well-known biochemistry textbooks like Lehninger, Stryer and Voet (Berg, Tymoczko and Stryer, 2002; Lehninger, Nelson and Cox, 2004; Voet and Voet, 2011).

Table 2: Predictive accuracy of the fundamental tenets of the two models.

\begin{tabular}{|c|c|c|c|}
\hline No. & Predictive Query & Relevant Facts & Direct deduction \\
\hline 1. & $\begin{array}{l}\text { If the ETC proteins pump } \\
\text { protons, mitochondria } \\
\text { must have ample free } \\
\text { protons. Further, the } \\
\text { reaction at the ETC } \\
\text { Complexes should afford } \\
\text { enough energy to pump } \\
\text { the required amounts of } \\
\text { protons. }\end{array}$ & $\begin{array}{l}\text { While several tens of } \\
\text { thousands of ETC proteins are } \\
\text { present in a mitochondrion, } \\
\text { protons are sparse (at } \\
\text { physiological pH). Only the } \\
\text { reaction at Comp. IV affords } \\
\text { the thermodynamic "window" } \\
\text { to pump two protons per } \\
\text { passage of electron. }\end{array}$ & $\begin{array}{l}\text { The murburn model does } \\
\text { not invoke proton pumps } \\
\text { and deems protons as a } \\
\text { limiting reactant. Thus, this } \\
\text { model can operate in the } \\
\text { practically aprotic } \\
\text { mitochondrial environment. }\end{array}$ \\
\hline 2. & $\begin{array}{l}\text { If the ETC proteins served } \\
\text { as ADP-binders and } \\
\text { DROS generators and/or } \\
\text { modulators, one would } \\
\text { expect ADP-binding sites } \\
\text { and DROS access } \\
\text { channels/cavities within } \\
\text { them. }\end{array}$ & $\begin{array}{l}\text { Earlier in vitro experimental } \\
\text { works have indicated the } \\
\text { presence of ADP-binding } \\
\text { sites on ETC Complexes. The } \\
\text { recent structural and in silico } \\
\text { works have pointed out the } \\
\text { loci of the ADP-sites and the } \\
\mathrm{O}_{2} \text {-accessible redox centers. }\end{array}$ & $\begin{array}{l}\text { The recent findings support } \\
\text { the murburn model. The } \\
\text { presence of } \mathrm{O}_{2} \text {-accessible } \\
\text { redox centers in proteins } \\
\text { discount the RCPE scheme. } \\
\text { Since proton-pumps are not } \\
\text { tenable, ETC complexes } \\
\text { serve no role other than } \\
\text { water formation. }\end{array}$ \\
\hline 3. & $\begin{array}{l}\text { If oxygen served only as } \\
\text { the terminal electron } \\
\text { acceptor and stayed } \\
\text { bound to Comp. IV alone, } \\
\text { other ETC complexes } \\
\text { should not generate } \\
\text { DROS. }\end{array}$ & $\begin{array}{l}\text { The highly mobile oxygen } \\
\text { being restricted to Comp. IV } \\
\text { alone has no chemical or } \\
\text { physical basis. Ample } \\
\text { experimental evidence show } \\
\text { that that Complexes I through } \\
\text { IV generate and modulate } \\
\text { DROS. }\end{array}$ & $\begin{array}{l}\text { The deterministic nature of } \\
\text { RCPE model does not } \\
\text { correspond to the facts. The } \\
\text { entry and outward leak of } \\
\text { protons at multiple points } \\
\text { supports the murburn model. }\end{array}$ \\
\hline
\end{tabular}




\begin{tabular}{|c|c|c|c|}
\hline 4. & $\begin{array}{l}\text { If DROS is the key } \\
\text { protagonist in mOxPhos, } \\
\text { DROS formation would } \\
\text { increase with higher } \\
\text { amounts of } \mathrm{NADH} / \mathrm{O}_{2} \text { in } \\
\text { mitochondria.. }\end{array}$ & $\begin{array}{l}\text { Higher amounts of NADH } \\
\text { and } \mathrm{O}_{2} \text { generate greater } \\
\text { amounts of DROS in } \\
\text { mitochondrial physiology. }\end{array}$ & $\begin{array}{l}\text { While the RCPE model does } \\
\text { not address mitochondrial } \\
\text { propensity for DROS } \\
\text { formation, murburn scheme } \\
\text { explains the mobility and } \\
\text { reactivity of oxygen, and } \\
\text { DROS formation. }\end{array}$ \\
\hline 5. & $\begin{array}{l}\text { If a proton-based TMP is } \\
\text { generated and sustained } \\
\text { across the inner } \\
\text { mitochondrial membrane } \\
\text { (between the matrix and } \\
\text { IMS), then the outer } \\
\text { mitochondrial membrane } \\
\text { should be impermeable to } \\
\text { protons (so that escape of } \\
\text { protons via the same is } \\
\text { prevented). }\end{array}$ & $\begin{array}{l}\text { The } \mathrm{pH} \text { of IMS in } \\
\text { mitochondria and periplasm } \\
\text { in prokaryotes equilibrates } \\
\text { with the pH of cytoplasm and } \\
\text { external medium respectively. } \\
\text { The TMP has been } \\
\text { demonstrated only between } \\
\text { matrix and cytoplasm. }\end{array}$ & $\begin{array}{l}\text { The reality/facts discount } \\
\text { the steady state tenability of } \\
\text { the RCPE model. Murburn } \\
\text { model states that a TMP } \\
\text { (across the matrix and } \\
\text { cytoplasm, not IMS) arises } \\
\text { due to the generation of } \\
\text { negatively charged DROS in } \\
\text { the matrix, not by a proton } \\
\text { differential. }\end{array}$ \\
\hline 6. & $\begin{array}{l}\text { If the TMP enables Comp. } \\
V \text { to change conformation } \\
\text { and binding affinities, it } \\
\text { must have a TMP sensor, } \\
\text { enabling it to temporally } \\
\text { modulate and shift } \\
\text { between its affinities for } \\
\text { ADP and ATP. }\end{array}$ & $\begin{array}{l}\text { The structures of several } \\
\text { ATPases are known now. } \\
\text { There are no components to } \\
\text { sense or tap any electro- } \\
\text { static/magnetic fields within } \\
\text { Complex V. A fluctuating } \\
\text { potential is not observed. } \\
\text { (Also, the proton numbers } \\
\text { within a mitochondrion } \\
\text { cannot account for the rate of } \\
\text { ATP-synthesis.) }\end{array}$ & $\begin{array}{l}\text { The TMP or proton-based } \\
\text { explanation cannot account } \\
\text { for physiological ATP } \\
\text { synthesis. This scenario is } \\
\text { incompatible with RCPE } \\
\text { model. DROS catalyzes the } \\
\text { ATP synthesis without a } \\
\text { proton gradient or TMP, } \\
\text { which supports the Murburn } \\
\text { Scheme. }\end{array}$ \\
\hline 7. & $\begin{array}{l}\text { If Comp. V is the } \\
\text { physiological ATP- } \\
\text { synthase, it would have } \\
\text { higher affinity for ADP, } \\
\text { when compared to ATP. }\end{array}$ & $\begin{array}{l}\text { Comp. V has more than ten } \\
\text { million folds higher affinity } \\
\text { for ATP (compared to ADP). } \\
\text { So, if Comp. V is an ATP } \\
\text { synthesizer, the mitochondrial } \\
\text { ATP levels must be lower } \\
\text { than ADP by several orders. }\end{array}$ & $\begin{array}{l}\text { The thermodynamic and } \\
\text { kinetic realities preclude the } \\
\text { RCPE model. However, it is } \\
\text { unclear how ADP or ATP } \\
\text { binding to Comp. V affects } \\
\text { the murburn model. }\end{array}$ \\
\hline 8. & $\begin{array}{l}\text { Can we get higher rate of } \\
\text { ATP-synthesis with } \\
\text { increased } \mathrm{NADH}+\mathrm{O}_{2} \text { ? } \\
\text { Vice versa, will the } \\
\text { addition of } \mathrm{ADP}+\mathrm{Pi} \\
\text { increase } \mathrm{NADH}+\mathrm{O}_{2} \\
\text { consumption? In the } \\
\text { RCPE model, ET rate, a } \\
\text { limiting criterion, is } \\
\text { independent of } \mathrm{ADP}+\mathrm{Pi} \text {. }\end{array}$ & $\begin{array}{l}\text { We get higher rate in both of } \\
\text { the physiological scenarios. } \\
\text { The limiting factors of } \\
\text { mOxPhos are proton } \\
\text { availability and CoQ mobility, } \\
\text { which are independent of } \\
\mathrm{NADH}+\mathrm{O}_{2} \text { or ADP+Pi } \\
\text { concentrations and/or } \\
\text { consumption. }\end{array}$ & $\begin{array}{l}\text { Since the ET and ATP- } \\
\text { synthesis are disconnected } \\
\text { in RCPE model, it cannot } \\
\text { explain the increase in } \\
\text { metabolic rate under the two } \\
\text { scenarios. The murburn } \\
\text { model posits that DROS } \\
\text { production causes a } \\
\text { thermodynamic pull that } \\
\text { catalyzes the ATP synthesis. }\end{array}$ \\
\hline
\end{tabular}




\begin{tabular}{lll}
\hline 9. $\begin{array}{l}\text { If DROS generates TMP } \\
\text { and catalyzes ATP } \\
\text { synthesis (murburn } \\
\text { model), one would predict } \\
\text { a direct correlation of } \\
\text { DROS with TMP and ATP } \\
\text { synthesis in a respiring } \\
\text { mitochondrion. }\end{array}$ & $\begin{array}{l}\text { In respiring mitochondria, } \\
\text { TMP generation and ATP } \\
\text { synthesis directly correlates } \\
\text { with DROS production. }\end{array}$ & $\begin{array}{l}\text { RCPE cannot explain this } \\
\text { outcome, whereas this result } \\
\text { is consistent with the } \\
\text { murburn model. }\end{array}$ \\
$\begin{array}{l}\text { If DROS serves to esterify } \\
\text { ADP with Pi in } \\
\text { mitochondrial physiology } \\
\text { (murburn model), can we } \\
\text { simulate the reaction in } \\
\text { vitro? }\end{array}$ & $\begin{array}{l}\text { Experimental evidence shows } \\
\text { that in mitochondria and in } \\
\text { vitro setups, superoxide }\end{array}$ & $\begin{array}{l}\text { Such observations downplay } \\
\text { to ADP (yielding ATP). }\end{array}$ \\
\hline
\end{tabular}

From the above, it can be seen that RCPE model fails to shoulder the fundamental mechanistic tenets it proposes. At the outset, murburn concept appears to be a more facile chemical logic that is neither self-contradictory nor does it seek insurmountable chemico-physical requisites.

\section{Murburn versus Chemiosmosis: Miscellaneous predictability of the two models}

Essentially, ATP synthesis is a chemical reaction occurring in space and time. So, the fundamental elements of this reaction are- the nature of the reaction vessel, the catalysts involved, and the reaction propensities of the reactants. Further, biochemistry relies on elucidating the reaction mechanism through incorporation of additives (inhibitors/modulators). So, the following discussion focuses on these areas as the criteria for the mechanistic differentiation of the two models. (The points are numbered starting from 11, to continue with the agenda of comparison started in Table 2.)

\section{Structure and distribution of ETC complexes in Mitochondria}

11. As per the RCPE model, a tightly packed system of protein complexes and a greater ratio of Comp. I /II (flavoprotein):Comp. IV (hemoprotein) is essential for an efficient ETC and electron transfer stoichiometry, respectively.

The distribution of respiratory proteins around the mitochondrial inner membrane is shown in Figure 3. The mean distance between the two nearest proteins/complexes ranges between $7-20$ 
$\mathrm{nm}$, and they are distributed at a density of $10^{10}$ to $10^{11}$ molecules per $\mathrm{cm}^{2}$ (occupying $\sim 50 \%$ surface area of the membrane). The range of protein complexes are $\sim 10^{4}-10^{5}$ per mitochondrion (Gupte et al., 1984; Schwerzmann et al., 1986). This means that RCPE model mandates that "batteries" (serially networked protein complexes) of $\sim 10^{4}-10^{5}$ ETC complexes exist per mitochondrion. The concentration of Comp. IV (DROS modulator) is significantly higher than Comp. I/II (primary ROS generators) (Schägger and Pfeiffer, 2001). Thus, the relative distribution densities of protein complexes and components support the murburn model. For the RCPE model to operate, the concentration of Complex I/II must be higher than that of Complex IV. Furthermore, the ratio of Comp. IV to Cyt. $c(1: 1.5)$ is disadvantageous for the RCPE model. The murburn scheme is a parallel system (unlike the serial arrangement of components in the RCPE model) and hence, the relative distribution densities of protein complexes and reaction rates are better explained by the murburn model (Manoj et al., 2019).
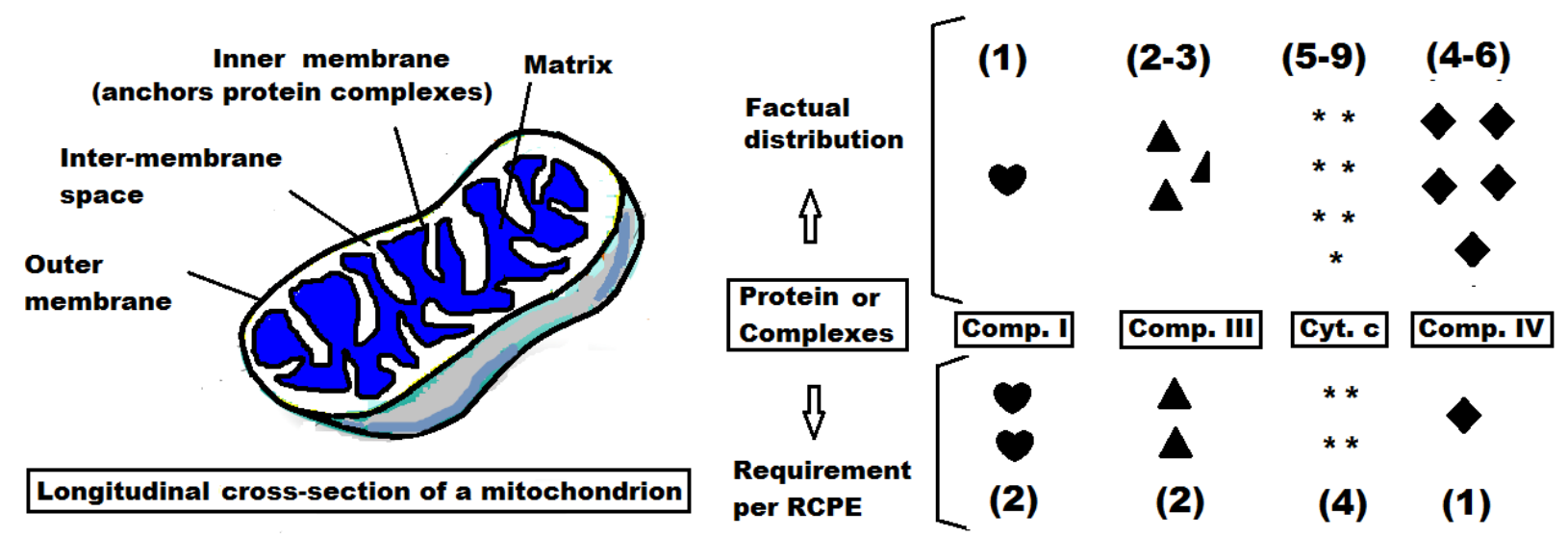

Figure 3: General architecture of a mitochondrion (A) and an analysis of the distribution ratios of key proteins $(B)$. The RCPE model posits a deterministic or fixed ratio of these protein complexes (2:2:4:1), while the actual distribution is quite the opposite. The murburn model supports the observed distribution of ETC (see text for details).

12. Since several electron transfer steps are rate limiting, one would imagine that the sequential ETC would get optimized through evolution to- (i) obviate connectivity issues, and (ii) minimize DROS formation. Also, for the proton gradient to form, there must be a modularized and synchronized network of the proton-pumping ETC-complexes.

The features of- (i) non-sophisticated architecture of mitochondria, (ii) random distribution of protein complexes in the membrane, (iii) requirement $2 \mathrm{CoQ}$ and 4 Cyt. $c$ molecules to ferry $4 \mathrm{e}^{-}$ 
for the reduction of one $\mathrm{O}_{2}$ molecule, (iv) the presence of non-favorable potential gradients and distances between redox centers, (v) non-reducible and non-route redox centers, (vi) requirement of protons within membrane embedded loci, etc. counter the sequential/serial and deterministic RCPE model. Mitochondria do not have nano-compartmentalization to generate multiple localized regions with fluctuating $\mathrm{pH}$. Further, it is not clear how the protein complexes could function serially, in the form a "battery", all the while avoiding DROS formation. Therefore, the reality seems to be a deliberate ploy by life's evolutionary principles to enable "a closed pot reaction" logic for achieving DROS-mediated ETs/catalysis. The structural aspects listed above support the murburn model and discount the RCPE model.

13. If Comp. I/II collect electrons (from NADH and succinate respectively) and pass it to the membrane-based CoQ, they would have a short matrix-arm (with occluded redox centers) and long trans-membrane foot with well-separated redox centers (to enable proton pumping).

A systematic comparison of minimal requirement of the structural attributes by the two models is shown in Figure 4. Both Comp. I \& II have a large bulbous matrix-ward extension with multiple redox centers. There is little structural attribute in the trans-membrane foot that suggests a proton pumping functionality. Since electron transfer rates are several orders faster than the purported proton pump rates, the two processes can't be spatio-temporally coupled. Therefore, how the RCPE model Complex I synchronizes ET and proton pumping is obscure. Murburn scheme seeks the generation of DROS by the two flavoenzymes of Comp. I and II (Manoj, Gade and Mathew, 2010; K.M. Manoj, Parashar, Gade, et al., 2016; Manoj et al., 2019). The presence of multiple redox centers in the matrix domains of Complex I and II aids DROS-generation (Hatefi, 1985; Grivennikova and Vinogradov, 2006; Quinlan et al., 2012; Manoj et al., 2019), which supports the murburn model (Figure 4 A). Especially, the RCPE model does not explain the functionality of the large matrix domain of Complex III (Figure 4B), which could well operate with just the trans-membrane domain of the Complex. The fact that the matrix domain of this complex houses ADP binding sites and cavities (enabling DROS-dynamics) (Manoj et al., 2019) supports the murburn model. In short, the matrix domains of Complexes I-IV house DROSgenerating/modulating redox centers and ADP binding sites, which are essential requisites of the murburn scheme. 
Erstwhile structure-function

A

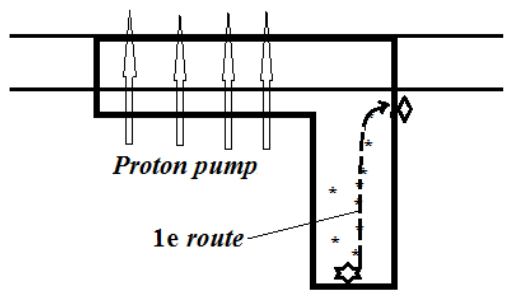

B

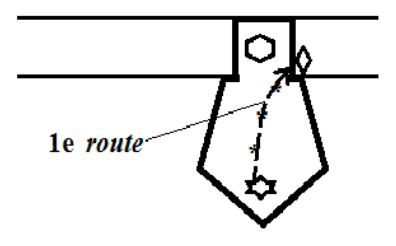

C

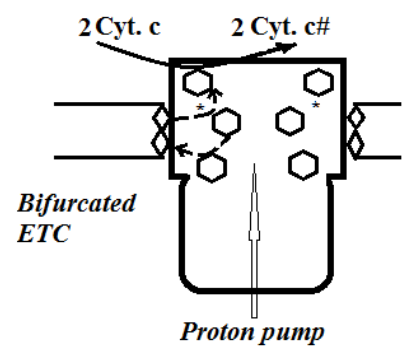

D

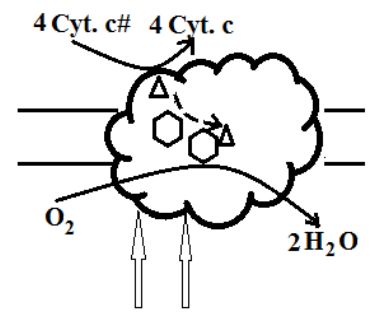

Proton pump

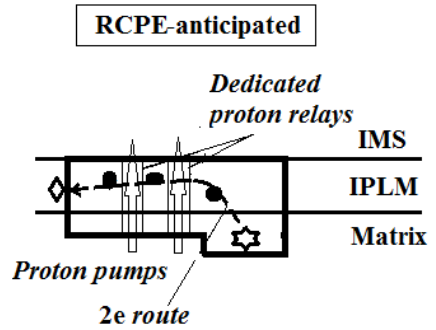

Complex I

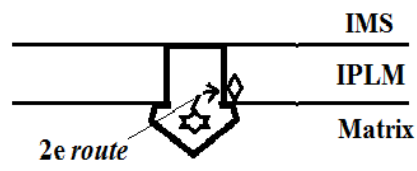

Complex II

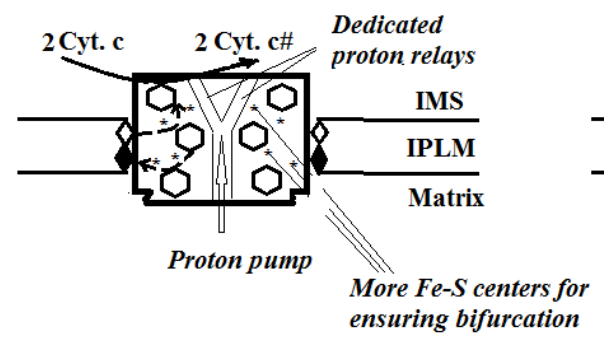

Complex III
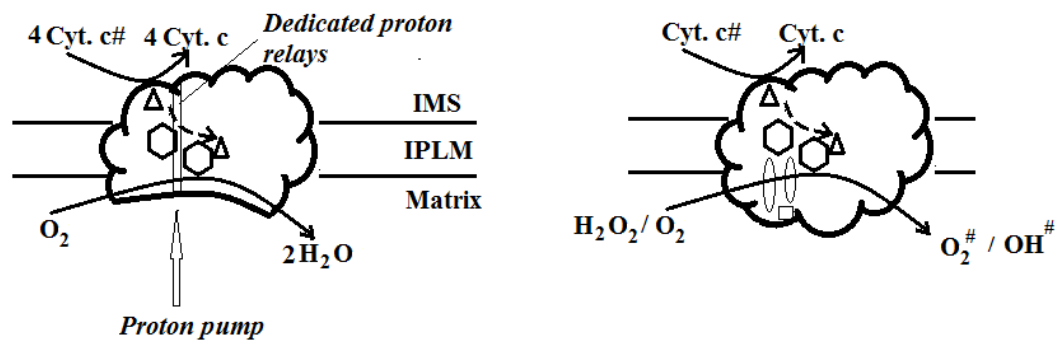

Complex IV

\begin{tabular}{|llcl|}
\hline Flavin & $*$ Fe-S center & $\diamond \operatorname{CoQ}\left(\mathrm{H}_{2}\right)$ & $\bullet$ 2e center \\
0 Heme & $\Delta$ Cu center & $\checkmark-*$ Internal e-route & Alternate 2e-acceptor
\end{tabular}

Figure 4: Comparison of structural attributes of the redox protein complexes (Complexes I to $I V)$ of mitochondrial aerobic respiration (A-D). RCPE mode deems the matrix domain of these complexes redundant. However, the presence of multiple redox centers and ADP binding sites in these domains supports the Murburn model. Only a single monomer's redox centers are depicted in Comp. IV (D). 
14. The RCPE model requires a mitochondrial membrane impermeable to protons, whereas the murburn model doesn't. Also, the RPCE model predicts/seeks the mitochondrial membranes to be highly restrictive to protons whereas, the murburn model doesn't. It is difficult to envisage that a non-specific inward proton flux (via the lipid membrane) can be prevented in a functional mitochondrion.

The overall equation of mOxPhos starting from NADH is proton deficient and the ETC concept clearly vouches for the separation of protons from electrons. Moreover, only close-packed membrane proteins could potentially restrict the proton influx. Protons generically permeate the phospholipid membrane to small levels, in millisecond time ranges (Biegel and Gould, 1981). As per the murburn model, reduced CoQ takes up such generic proton influx. Accounting for proton availability and dynamics is the biggest handicap of the proton-centric RCPE model.

15. As per the murburn model, how does the mitochondrial membrane adapt to the formation and stabilization of DROS in mOxPhos?

The preponderance of cardiolipin, a special phospholipid, affords high negative charge densities at the membrane interface, which retains negatively charged species within the matrix. Since the RCPE model seeks both inward and outward proton flow, it cannot explain the presence of cardiolipin and evolutionary conservation of this lipid in mitochondria. The distribution of cardiolipin is conserved across the mitochondrial and prokaryotic membranes alike, which suggests its DROS-restrictive significance in the ubiquitous mOxPhos physiology. CoQ can also scavenge DROS that otherwise manages to collide with the membrane.

\section{Different aspects of the reaction chemistry and the effect of additives}

16. Since the deterministic RCPE model has definitive distribution of ETC and defined $2 e$ reaction equations, it should have well-defined stoichiometries $(P / O$ and $H / P)$ for both succinate and NADH.

Studies across labs show variable and non-integral stoichiometries (H:P or O:P) in mOxPhos (Hinkle, 2005; Watt et al., 2010) and this does not support the deterministic $2 \mathrm{e}^{-}$scheme of RCPE, which also advocates proton pumps to work at batches of 4 or 2 . The lack of a well- 
defined stoichiometry (and thereby the difficulty in arriving at precision or accuracy) is the classical signature of a stochastic murburn scheme.

17. The RCPE model predicts a constant (high) loss of redox equivalents at all times, in the presence or absence of $A D P+P i$.

The depletion rate of NADH is higher and lower respectively in the presence and absence of ADP+Pi (Manoj, 2017; Manoj et al., 2019). The redox-pull mechanism of murburn model explains this observation, which is quite analogous to the microsomal xenobiotic metabolism (K.M. Manoj, Parashar, Gade, et al., 2016).

18. Any disruption in mitochondrial membrane affects the RCPE model as it requires an ordered arrangement of protein complexes.

Membrane disruption does not significantly affect the depletion of NADH and consumption of oxygen (Berg, Tymoczko and Stryer, 2002; Lehninger, Nelson and Cox, 2004; Voet and Voet, 2011). The RCPE model requires ordered arrangement protein complexes and movement of its essential components, which means that any deviation from this deterministic model critically affect the depletion of NADH and consumption of oxygen.

19. According to classical kinetics (RCPE model), the $K_{d}$ of oxygen binding (equilibrium dissociation constant) with Complex IV should be lower than $K_{M}$ (Michaelis constant).

Quite unusually, $\mathrm{K}_{\mathrm{d}} \gg \mathrm{K}_{\mathrm{M}}$ for oxygen's interaction with Comp. IV (Orii, 1988; Manoj et al., 2019). This maverick fact supports the murburn model of mOxPhos and negates the RCPE model.

20. If Marcus electron transfer theory were relevant for all steps, then anoxic ET between each or every two redox centers in the route should at least be in the same order as the overall ETC rate.

The anoxic ET between the two heme $a$ of Comp. IV afforded several orders lower rates when compared to the overall ETC rates (Orii, 1988). This finding counters the deterministic ET scheme of RCPE. The ET paradigm could be explained by murburn model. 
21. If the electron transport works as per the murburn model, we would expect maverick concentration- and dose-dependent effects of various amphipathic toxins and uncouplers such as disubstituted phenolics.

Maverick concentration-dependent effects were reported in biological phosphorylations by various groups in the 1960s to 1970s (Avron and Shavit, 1965; Watling-Payne and Selwyn, 1974), only to be side-tacked as artifacts. A dose-dependent effect of amphipathic respiratory toxins and uncouplers of electron transport chain has been reported before (Kovacic et al., 2005; Manoj, 2018b). Disubstituted phenolics are uncouplers in xenobiotic metabolism mediated in microsomes too (Tokutake, Miyoshi and Fujita, 1991; Parashar, Gade, et al., 2014). These observations support the operational relevance of murburn concept. Dynamic DROS modulation at the phospholipid interface could explain such effects.

22. If cyanide inhibited mOxPhos by the RCPE model (via binding to the heme center of Complex IV), then the toxicity levels for cyanide administration would approach $\mathrm{g} / \mathrm{Kg}$ doses (because the effective $K_{d}$ of cyanide would be in high millimolar ranges).

The oral/blood toxicity of cyanide falls in $\mathrm{mg} / \mathrm{Kg}$ ranges discounts the relevance of RCPE mechanism (Manoj et al., 2019). Since cyanide is not supposed to bind with Complexes I, II, III, and V (Way, 1984), the first three proton pumps should enable ATP production via the influx of protons through Complex V, as the RCPE model suggests. Oxygen accepts electrons from Complexes I-III too, and if the RCPE model is valid, the proton pumps should theoretically work and the Complex V should synthesize ATP. But aerated and NADH replenished mitochondrial systems do not show ATP formation in the presence of cyanide (Aw and Jones, 1989). The low lethal dose of cyanide implicates the diffusible role of cyanide (Parashar, Venkatachalam, et al., 2014; Manoj et al., 2019) in DROS mediated ATP synthesis and thereby ratifies the relevance of murburn model. Thus, the findings also negate the RCPE hypothesis.

23. If murburn model explains the phosphorylation chemistry, we could also observe nonspecific phosphorylations in biological systems with DROS-generating agents. 
ROS-associated non-specific phosphorylation of hydroxyl groups of amino acids and xenobiotics have been noted in literature (Spudich and Stoeckenius, 1980; Stadtman and Levine, 2003; Uchida, 2003; Mitchell, 2016), which reinforces the operational relevance of murburn model.

24. If a diffusible reactive species were involved in oxidative phosphorylation, one would expect to get several labeled oxygen atom's incorporation in ATP. If DROS chemistry were involved in the uncoupling phenomena, we could expect to see uncouplers inhibiting phosphorylations in other reaction systems too (which do not invoke the relevance of TMP/proton pumps).

Such observations have been reported in the field by several researchers from the 1950s to 1970s, particularly pioneered by Mildred Cohn (Cohn, 1953). These observations are one of the strongest mechanistic evidences of murburn concept's relevance in mOxPhos.

25. If murburn model were to be relevant, a DROS generator and an ATPase can synthesize ATP in a closed vesicular system.

The famed Racker's experiment (Racker and Stoeckenius, 1974) and the recent Otrin's demonstration of reconstituting ATP synthesis activity in vesicles with only oxidase and Complex V (Otrin et al., 2017) support the murburn model.

26. If murburn scheme were operational, one would expect shorter life spans for animals with high metabolic rate.

This is in fact the statistical case in nature (Olshansky and Rattan, 2009) and therefore, the physiological and evolutionary relevance of murburn model is ratified.

27. The operating logic of the oxygen-centric concept invokes a hearth or nuclear reactor type of working principle.

The logic of RCPE model of mOxPhos is analogous to an automobile or hydroelectric power plant. However, a spontaneously formed automobile (with synchronized functions of engine, battery, dynamo, sensors/controllers, etc.) or hydroelectric power plant (employing the gambits of pumping something upstream first and then harvesting its flow in a purported flow downstream) does not exist. While the hearth or grill is a simple comparison, the nuclear reactor is a sophisticated analogy for the murburn mOxPhos system. There are countless examples of the 
natural/spontaneous formation of a hearth or grill. The rare example of the spontaneous formation of a natural nuclear reactor (Oklo, Gabon) also lends support for the machine logic of murburn explanation of mOxPhos (Manoj, 2018b).

28. When life evolved in the primordial times, highly specific affinity-based reactions based on topological and electrostatic complementation could not have existed.

The fact that the biological ETC can take in and give out electrons through several man-made molecular/radical species (Hauska, 1977) vouches for a non-specific one-electron reaction paradigm. Such observations strengthen the relevance of murburn model in mOxPhos.

29. The overall yield of ATP production from the complete oxidation of glucose to $\mathrm{CO}_{2}$ is about 40\%. Therefore, since mOxPhos is in the last step of the overall metabolic cascade (after glycolysis and Krebs cycle), the yield of mOxPhos should be much higher than $40 \%$.

Theoretically, the yield of mOxPhos is only $40 \%$. Therefore, it cannot explain the higher efficiencies required and experimentally reported by several workers (Lee et al., 1996). Through augmentation of metabolic control and optimization of diffusible radical species, the high efficiency of mOxPhos is achieved.

30. The respiratory ATP synthesis in anaerobic micro-organisms does not involve oxygen or DROS. This could implicate that murburn concept is not an evolvable or conserved mechanism. Murburn scheme is essentially a molecule-ion-radical interactive scheme. In anaerobic prokaryotes, other components (sulfur and nitrogen centered species, for example) could suit the roles played by oxygen-centered protagonists in eukaryotic mitochondria. However, the mobility and discharge of the reactants and end-products (larger and precipitating species) would be a slower process, thereby explaining the slow metabolic rate of anaerobic systems.

\section{Further experimentations proposed to demarcate the two models}

In the near future, experiments detailed below could potentially ratify the relevance of murburn concept in mOxPhos and differentiate the two models. 
* The arguments professed herein can be further confirmed by employing- (a) chemical controls and reductionist approach, within controlled-water systems like normal/reverse micelles, with DROS generating/stabilizing systems involving proteins containing $\mathrm{Mg} / \mathrm{Fe} /$ peroxide / $\mathrm{NADH}$ / superoxide / pyrithione-photolysis (as a hydroxyl radical source) and substrate analogs. (b) proteins can be engineered to incorporate a flavin and a heme cofactor with surface ADP-binding sites, in conjunction with a proton-delivering system, to demonstrate ATP synthesis in closed vesicles. (Details for protocols are provided in KMM's original arxiv preprint available athttps://arxiv.org/ftp/arxiv/papers/1703/1703.05827.pdf)

* Amphipathic DROS modulating molecules (like vitamin E and fatty acyl vitamin C) and transmembrane helix containing redox-active enzymes (like horseradish peroxidase) inhibit membrane-embedded electron transport and redox metabolism in microsomal xenobiotic metabolic (mXM) system (Parashar, Gade, et al., 2014); whereas their soluble functional analogs (trolox, ascorbate, and superoxide dismutase) don't inhibit (K.M. Manoj, Parashar, Venkatachalam, et al., 2016) the same. Further, many of these inhibitions exhibit a maverick concentration-dependent profile ( $\mathrm{mM}$ to $\mathrm{pM})$. Such effects of various uncoupling molecules can be further probed and demonstrated in the mOxPhos system. A similar set of reactions could be repeated in a minimalistic model like the Racker's/Otrin's experiment. In conjunction, the inhibitory capacity of retinol, retinal and retinoic acids and their esters could also be compared.

* Evolutionary-lineage analysis of respiratory complexes may give evidence of DROS modulation machinery's progression and specific adaptation across domains in various species.

* The new paradigm permits the mitochondria to work even without a $\mathrm{pH}$ gradient, at low proton concentrations and without high trans-membrane potentials. This projection can be ratified in simple experimental systems. [Jagendorf's experiment (Jagendorf and Uribe, 1966) can be redone by equilibrating mitochondria at $\mathrm{pH} 6$ and then providing an external buffer of $\mathrm{pH} 4$. The rates obtained above could be compared with an experiment where the mitochondria are equilibrated at $\mathrm{pH} 8$ and then exposed to a buffer at $\mathrm{pH}$ 6. Such proton-gradients would be inadequate to power ATP synthesis (Manoj, 2017) per the chemiosmosis hypothesis even from 
the initialized state. But yet, we may observe a net equilibrium-driven ATP synthesis, indicating the inapplicability of chemiosmosis hypothesis.]

* It can be explored if Complex III can set a one-electron scheme from $\mathrm{CoQH}_{2}$ and $\mathrm{H}_{2} \mathrm{O}_{2}$ in the presence of oxygen+NADH. Further, this Complex's ability to bind ADP (as predicted by murburn scheme) can be explored.

* Cyanide is the most potent cellular respiratory toxin (Nelson, 2006) and therefore, it is perhaps the most important tool to investigate the mechanism of mOxPhos. The following experiments are suggested to further ratify the proposals/deductions of the current work on the impact of cyanide on cellular respiration and toxicity.

* In a simple reductionist system, the inhibitory role of cyanide in ATP synthesis can be traced. To a control reaction of $\mathrm{ADP}+\mathrm{Pi}+$ superoxide, a test reaction of $\mathrm{ADP}+\mathrm{Pi}+$ superoxide+cyanide can be compared.

* In respiring cells or mitochondrial suspension, (sub)micromolar levels of cyanide should be presented and consumption of oxygen and formation of DROS noted. While the binding-based perspective projects cell death and cessation of respiration, the new proposal predicts oxygen consumption leading to DROS formation (albeit at low levels).

* The catalytic role of cyanide radical/DROS can be traced by the incorporation of radiolabeled carbon in cyanide or radio-labeled oxygen. After exposing an experimental system to the molecular probes, the radio-labeled cyanate formation can be traced to confirm the radical pathway of CN/oxygen interaction. On the other hand, if $\mathrm{CN}$ binding to heme is efficient and irreversible, cyanate should not be formed.

* Similarly, if the efficient competitive ligand CO bound that effectively, one should not have DROS production and thereafter, a dissipation reaction of the equation scheme$\mathbf{2 C O}+\mathrm{OH}^{*}+\mathrm{O}_{2}{ }^{*-} \rightarrow \mathrm{HCO}_{3}{ }^{-}+\mathrm{CO}_{2}$. Confirmation of the radical chemistry can be done with $\mathrm{H}_{2} \mathrm{~S}$ and $\mathrm{CO}$, by tracing the radio-labeling of $\mathrm{C} / \mathrm{S}$ and $\mathrm{O}$ atom within $\mathrm{SO}_{2} /$ sulfate and 
$\mathrm{CO}_{2} /$ carbonate, respectively. It is expected that while $\mathrm{H}_{2} \mathrm{~S}$ would be highly metabolized, $\mathrm{CO}$ would be much lesser converted (as it is a better binder and poorer substrate). This could also be because the $\mathrm{Hb}$ in the blood would take up significant amounts of $\mathrm{CO}$, and they do not have mitochondria to metabolize via DROS. (This would also explain the evolutionary reason for the higher affinities of $\mathrm{Hb}$ for $\mathrm{CO}$, in comparison to Cox.) But per the murburn perspective, a mitochondrial suspension would surely oxidize $\mathrm{CO}$ to $\mathrm{CO}_{2}$ and carbonate. Else, we cannot explain the reversal of toxicity in CO-exposed animals and individuals.

* Per the erstwhile purview, since cyanide has no bearing with Complexes I, II, \& III (and since the purported ETC works without push or pull), these proteins should assist Complex V produce ATP via the "proton-based machinery", if the old mechanisms were operative. So, at $\mathrm{K}_{\mathrm{d}}(\mathrm{mM})$ concentrations of cyanide taken experimentally (Antonini et al., 1971), only 50\% of Complex IV is 'bound by cyanide'. That would still leave 1:12:2-3:2-3:4-6:5-9 ratio of the complexes (I:II:III:IV:V:Cyt.c) in the mitochondrial suspension, and only a minimal or stoichiometric loss of activity should be noted. The new scheme predicts an overwhelming loss (practical cessation) in the ATP production ability of the system.

* A 'cyanide-blocked' system could be subjected to a favorable external $\mathrm{pH}$ gradient (say, 6.5 out to 9.5 in), quite similar to the demonstration by Mitchell's group or a rhodopsin assisted ATP-synthesis via Racker-Stoeckinius type setups (Racker and Stoeckenius, 1974). While the erstwhile hypothesis does not seek inhibitions, the new perspective advocates cessation of fresh ATP synthesis.

* In any experimental system above, cyanide could demonstrate a maverick concentration-based modulatory effect. Say, at concentrations near nM levels of cyanide, murburn concept may result in an interesting observation that ATP synthesis could even be enhanced by a small fraction (say, up to $20 \%$ ). 
* The multi-molecular Q-Cycle scheme of binding of a molecule each of CoQ, $\mathrm{CoQH}_{2}$ and Cyt. c to the TM region of Complex III can be reinvestigated through experimental modeling and simulation. Molecular simulations of $\mathrm{CoQ}\left(\mathrm{H}_{2}\right)$ diffusion in the phospholipid bilayer and binding to various proposed regions of the respiratory complexes should be revisited, owing to clear doubts that had been expressed in the field by renowned workers (Gupte et al., 1984; Chazotte and Hackenbrock, 1989). Similarly, the diffusion and binding of cytochrome $\mathrm{c}$ and binding with Complexes III \& IV should be simulated.

\section{Summation}

Since DROS catalyzes the synthesis of ATP in both reductionist and in situ systems, the case for murburn model is also strong because of the following-

1. Mitochondria (and each one of the four protein complexes) generate ROS, in the presence of NADH and oxygen (Ksenzenko et al., 1992; Grivennikova and Vinogradov, 2006; Quinlan et al., 2012; Bleier and Dröse, 2013).

2. The concentration of superoxide/peroxide (reactive oxygen species) produced is directly proportional to the NADH and oxygen presented (Murphy, 2009; Manoj et al., 2019).

3. The magnitude of TMP and the amount of ATP synthesized is directly proportional to the ROS detected (Nicholls, 2004). ATP cannot be synthesized without the production of DROS.

4. The following equation, one which involves the intermediacy and formation of DROS better explains mOxPhos chemistry. It is an example that agrees with bond energetics, accounts for the reported higher efficiency of mOxPhos, connectivity of electron transport and ATP synthesis, overall phenomenology, and the role of Complex V (coupling agent serving protons in the steady state):

$$
\mathrm{NADH}+4 \mathrm{ADP}+4 \mathrm{Pi}+\mathrm{O}_{2} \rightarrow \mathrm{NAD}^{+}+4 \mathrm{ATP}+\mathrm{H}_{2} \mathrm{O}_{2}+3 \mathrm{H}_{2} \mathrm{O}+\mathrm{OH}^{-}
$$

5. KMM's earlier works established that the non-active site and diffusible species mediated enzyme catalysis is an effective physiological modality. The prevailing perception that DROS are predominantly dangerous to life is not based on sound chemical or quantitative rationale (Ristow and Schmeisser, 2011; Mittler, 2017). In combustion, oxygen-centered radicals react among themselves to generate heat and form water. This is a common place phenomenon such as combustion or burning of wood. Therefore, an analogous but milder phenomena happens in cellular respiration. Heat generation in cellular respiration results from DROS reaction amongst 
themselves, thereby confirming the observed outcomes and murburn model that NADH equivalents go into ATP formation or/and heat generation (Manoj, 2017; Manoj et al., 2019).

Therefore, with respect to theoretical foundations (adherence to known chemico-physical laws) and current experimental data, the comprehensive aspects of the two models are summated below in Table 3.

Table 3: Holistic perspectives of the two models

\begin{tabular}{|c|c|c|c|}
\hline No. & Aspect & RCPE model & Murburn model \\
\hline 1. & $\begin{array}{l}\text { Thermodynamics } \\
\text { \& kinetics }\end{array}$ & $\begin{array}{l}\text { Unviable because an inherently } \\
\text { endergonic process (matrix- } \\
\text { ward movement of pumped out } \\
\text { IMS proton) cannot support } \\
\text { another endergonic reaction } \\
\text { (synthesis of ATP). } \\
\text { Multi-molecular two-electron } \\
\text { reaction scheme with CoQ cycle } \\
\text { is too slow to explain for the } \\
\text { overall reactivity. }\end{array}$ & $\begin{array}{l}\text { The overall reaction is driven by } \\
\text { water }(\mathrm{O}-\mathrm{H} \text { bond) formation in } \\
\text { matrix and its subsequent efflux } \\
\text { via aquaporins. The fast bi- } \\
\text { molecular/radical reactions } \\
\text { support the outcomes. }\end{array}$ \\
\hline 2. & $\begin{array}{l}\text { Working logic } \\
\text { and architecture } \\
\text { of the protein } \\
\text { complexes }\end{array}$ & $\begin{array}{l}\text { On one hand, the deterministic } \\
\text { scheme (with sequential or } \\
\text { concerted array and ordered } \\
\text { events) makes the system } \\
\text { irreducibly complex and poses } \\
\text { evolutionary constraints. On the } \\
\text { other hand, the random } \\
\text { distribution of components and } \\
\text { non-sophisticated structures } \\
\text { make the mechanism non- } \\
\text { viable. }\end{array}$ & $\begin{array}{l}\text { Simple stochastic scheme } \\
\text { (unordered events with } \\
\text { independent components) is } \\
\text { favored by probability. } \\
\text { Evolvable from a minimal set; } \\
\text { distribution of components } \\
\text { favorable. }\end{array}$ \\
\hline 3. & $\begin{array}{l}\text { Agreement with } \\
\text { experimental } \\
\text { information \& } \\
\text { overall } \\
\text { coherence }\end{array}$ & $\begin{array}{l}\text { While several observations are } \\
\text { inexplicable, some observations } \\
\text { counter the model. } \\
\text { Unviable with known chemico- } \\
\text { physical fundamentals and } \\
\text { inherently self-contradictory. }\end{array}$ & $\begin{array}{l}\text { Most observations reported till } \\
\text { date are adequately explained } \\
\text { with no logical contradictions }\end{array}$ \\
\hline
\end{tabular}

\section{Conclusions}

Approximately thirty distinct predictions were seen to ratify the murburn scheme for mOxPhos, as opposed to the chemiosmosis explanation. While the RCPE model (or any proton motive force 
or/and trans-membrane potential based explanation) appears highly misplaced, the murburn model does not pose major issues with known theoretical ideas and experimental facts. Of course, murburn scheme could also be proven wrong in the future, but for the same, the onus to propose a new explanation lies on the next one who can challenge it and prove that the murburn model is non-viable. Currently, the murburn model for mOxPhos needs more experiments and theoretical explorations to provide greater details of the working principles. For example- it is not clear as to what exact species are generated within the milieu, how does ADP/ATP binding influence the performance of Comp. V?, etc. It is envisaged that we would avail better insights in biology and medicine if all concerned warm up to the tenets of the new proposals.

Acknowledgments: KMM dedicates this manuscript to the memories of Lowell Hager (UIUC). It was Dr. Govindjee's (University of Illinois-UC, USA) suggestion that led to the realization of this manuscript. The work was powered by Satyamjayatu: The Science \& Ethics Foundation.

\section{References}

Andrew, D., Hager, L. and Manoj, K. M. (2011) 'The intriguing enhancement of chloroperoxidase mediated one-electron oxidations by azide, a known active-site ligand', Biochemical and Biophysical Research Communications, 414, pp. 646-649.

Antonini, E. et al. (1971) 'The interaction of cyanide with cytochrome oxidase', European Journal of Biochemistry, 23(2), pp. 396-400.

Avron, M. and Shavit, N. (1965) 'Inhibitors and uncouplers of photophosphorylation', Biochimica et Biophysica Acta (BBA)-Biophysics including Photosynthesis, 109(2), pp. 317-331.

Aw, T. Y. and Jones, D. P. (1989) 'Cyanide toxicity in hepatocytes under aerobic and anaerobic conditions’, American Journal of Physiology-Cell Physiology, 257(3), pp. C435-C441.

Berg, J. M., Tymoczko, J. L. and Stryer, L. (2002) Biochemistry. 5th. New York: WH Freeman.

Biegel, C. M. and Gould, J. M. (1981) 'Kinetics of hydrogen ion diffusion across phospholipid vesicle membranes', Biochemistry, 20(12), pp. 3474-3479.

Bleier, L. and Dröse, S. (2013) 'Superoxide generation by complex III: from mechanistic rationales to functional consequences', Biochimica et Biophysica Acta (BBA) - Bioenergetics, 1827(11), pp. 1320-1331.

Boyer, P. D. (1997) 'The ATP synthase - a splendid molecular machine', Annual Review of Biochemistry, 66(1), pp. 717-749. 
Chazotte, B. and Hackenbrock, C. R. (1989) 'Lateral diffusion as a rate-limiting step in ubiquinone-mediated mitochondrial electron transport', Journal of Biological Chemistry, 264(9), pp. 4978-4985.

Cohn, M. (1953) 'A study of oxidative phosphorylation with O18-labeled inorganic phosphate', Journal of Biological Chemistry, 201(2), pp. 735-750.

Fiedorczuk, K. et al. (2016) 'Atomic structure of the entire mammalian mitochondrial complex I’, Nature, 538(7625), pp. 406-410.

Gade, S. K., Bhattacharya, S. and Manoj, K. M. (2012) 'Redox active molecules cytochrome c and vitamin $\mathrm{C}$ enhance heme-enzyme peroxidations by serving as non-specific agents for redox relay', Biochemical and Biophysical Research Communications, 419, pp. 211-214.

Gideon, D. A. et al. (2012) 'What is the functional role of N-terminal transmembrane helices in the metabolism mediated by liver microsomal cytochrome P450 and its reductase?', Cell Biochemistry and Biophysics. 2012/02/04, 63(1), pp. 35-45. doi: 10.1007/s12013-012-9339-0.

Grivennikova, V. G. and Vinogradov, A. D. (2006) 'Generation of superoxide by the mitochondrial Complex I', Biochimica et Biophysica Acta (BBA) - Bioenergetics, 1757(5), pp. $553-561$.

Gupte, S. et al. (1984) 'Relationship between lateral diffusion, collision frequency, and electron transfer of mitochondrial inner membrane oxidation-reduction components', Proceedings of the National Academy of Sciences, 81(9), pp. 2606-2610.

Hatefi, Y. (1985) 'The mitochondrial electron transport and oxidative phosphorylation system', Annual Review of Biochemistry, 54(1), pp. 1015-1069.

Hauska, G. (1977) 'Artificial acceptors and donors', in Trebst, A. and Avron, M. (eds) Encyclopedia of Plant Physiology. Berlin: Springer Berlin Heidelberg, pp. 253-265.

Hinkle, P. C. (2005) 'P/O ratios of mitochondrial oxidative phosphorylation', Biochimica et Biophysica Acta (BBA) - Bioenergetics, 1706(1), pp. 1-11.

Jagendorf, Andr. T. and Uribe, E. (1966) 'ATP formation caused by acid-base transition of spinach chloroplasts', Proceedings of the National Academy of Sciences, 55(1), pp. 170-177.

Junge, W., Schliephake, W. D. and Witt, H. T. (1968) 'Experimental evidence for the chemiosmotic hypothesis', in Progress in Photosynthesis Research, Proceedings of the International Congress, pp. 1383-1391.

Kovacic, P. et al. (2005) 'Mechanism of mitochondrial uncouplers, inhibitors, and toxins: focus on electron transfer, free radicals, and structure-activity relationships', Current Medicinal Chemistry, 12(22), pp. 2601-2623.

Ksenzenko, M. Y. et al. (1992) 'Cytochrome oxidase-catalyzed superoxide generation from hydrogen peroxide', FEBS Letters, 297(1-2), pp. 63-66. 
Lee, C. P. et al. (1996) ' $\mathrm{P} / \mathrm{O}$ ratios reassessed: mitochondrial $\mathrm{P} / \mathrm{O}$ ratios consistently exceed 1.5 with succinate and 2.5 with NAD-linked substrates', The FASEB Journal, 10(2), pp. 345-350.

Lehninger, A. L., Nelson, D. L. and Cox, M. (2004) Principles of Biochemistry. Palgrave Macmillan Limited. Available at: https://books.google.co.in/books?id=XdeDGwAACAAJ.

Liberman, E. A., Topaly, V. P. and Tsofina, L. M. (1969) 'Mechanism of coupling of oxidative phosphorylation and the membrane potential of mitochondria', Nature, 222, pp. 1076-1078.

Ling, G. N. (1981) 'Oxidative phosphorylation and mitochondrial physiology: a critical review of chemiosmotic theory, and reinterpretation by the association-induction hypothesis', Physiol. Chem. Phys, 13(1), pp. 29-96.

Manoj, K. M. et al. (2010) 'Explaining the atypical reaction profiles of heme enzymes with a novel mechanistic hypothesis and kinetic treatment', PloS One, 5(5), p. e10601.

Manoj, K.M., Parashar, A., Venkatachalam, A., et al. (2016) 'Atypical profiles and modulations of heme-enzymes catalyzed outcomes by low amounts of diverse additives suggest diffusible radicals' obligatory involvement in such redox reactions', Biochimie, 125. doi: 10.1016/j.biochi.2016.03.003.

Manoj, Kelath Murali et al. (2016) 'Electron transfer amongst flavo-and hemo-proteins: diffusible species effect the relay processes, not protein-protein binding', RSC Advances, 6(29), pp. 24121-24129.

Manoj, K.M., Parashar, A., Gade, S. K., et al. (2016) 'Functioning of microsomal cytochrome P450s: Murburn concept explains the metabolism of xenobiotics in hepatocytes', Frontiers in Pharmacology, 7(JUN). doi: 10.3389/fphar.2016.00161.

Manoj, K. M. (2017) 'Debunking chemiosmosis and proposing murburn concept as the explanation for cellular respiration', Biomedical Reviews, 28, pp. 35-52.

Manoj, K. M. (2018a) 'Aerobic Respiration: Criticism of the Proton-centric Explanation Involving Rotary Adenosine Triphosphate Synthesis, Chemiosmosis Principle, Proton Pumps and Electron Transport Chain', Biochemistry insights, 11, p. 1178626418818442.

Manoj, K. M. (2018b) 'The ubiquitous biochemical logic of murburn concept', Biomedical Reviews, 29, pp. 89-97.

Manoj, K. M. et al. (2019) 'Aerobic respiration: proof of concept for the oxygen-centric murburn perspective', Journal of Biomolecular Structure and Dynamics, pp. 1-15.

Manoj, K. M., Gade, S. K. and Mathew, L. (2010) 'Cytochrome P450 reductase: a harbinger of diffusible reduced oxygen species’, PloS One, 5(10), p. e13272.

Manoj, K. M., Gideon, D. A. and Jacob, V. D. (2018) 'Murburn scheme for mitochondrial thermogenesis', Biomedical Reviews, 29, pp. 73-82. 
Manoj, K. M. and Hager, L. P. (2001) 'Utilization of peroxide and its relevance in oxygen insertion reactions catalyzed by chloroperoxidase', Biochimica et Biophysica Acta (BBA) Protein Structure and Molecular Enzymology, 1547(2), pp. 408-417.

Manoj, K. M. and Hager, L. P. (2008) 'Chloroperoxidase, a Janus Enzyme’, Biochemistry, 47(9), pp. 2997-3003.

Manoj, K. M., Parashar, A. and Venkatachalam, A. (2015) 'Going beyond Fisher/Koshland mechanisms and Michaelis-Menten kinetics: A new paradigm better explains Cytochrome P450 mediated drug metabolism', in 35th Midwest Enzyme Chemistry Conference. Chicago, USA.

Manoj, K. M., Venkatachalam, A. and Parashar, A. (2016) 'Metabolism of xenobiotics by cytochrome P450: novel insights into the thermodynamics, kinetics and roles of redox proteins and diffusible reactive species', in Drug Metabolism Reviews. Taylor \& Francis Ltd 2-4 Park Square, Milton Park, Abingdon Or14 4rn, Oxon, England, pp. 41-42.

Mitchell, P. (1961) 'Coupling of phosphorylation to electron and hydrogen transfer by a chemiosmotic type of mechanism', Nature, 191(4784), pp. 144-148.

Mitchell, S. C. (2016) 'Xenobiotic conjugation with phosphate-a metabolic rarity', Xenobiotica, 46(8), pp. 743-756.

Mittler, R. (2017) 'ROS Are Good', Trends in Plant Science, 22(1), pp. 11-19. doi: https://doi.org/10.1016/j.tplants.2016.08.002.

Murphy, M. P. (2009) 'How mitochondria produce reactive oxygen species', Biochemical Journal, 417(1), pp. 1-13.

Nałęcz, M. J. (1986) 'Is there sufficient experimental evidence to consider the mitochondrial cytochrome bc1 complex a proton pump? Probably no', Journal of Bioenergetics and Biomembranes, 18(1), pp. 21-38.

Nath, S. (2010) 'Beyond the Chemiosmotic Theory: Analysis of Key Fundamental Aspects of Energy Coupling in Oxidative Phosphorylation in the Light of a Torsional Mechanism of Energy Transduction and ATP Synthesis-Invited Review Part 1', Journal of Bioenergetics and Biomembranes, 42(4), pp. 293-300. Available at: http://dx.doi.org/10.1007/s10863-010-9296-5.

Nelson, L. (2006) 'Acute cyanide toxicity: mechanisms and manifestations', Journal of Emergency Nursing, 32(4), pp. S8-S11.

Nicholls, D. G. (2004) 'Mitochondrial membrane potential and aging', Aging cell, 3(1), pp. 3540.

Olshansky, S. J. and Rattan, S. I. S. (2009) 'What determines longevity: metabolic rate or stability?', Discovery Medicine, 5(28), pp. 359-362.

Orii, Y. (1988) 'Early molecular events in the reaction of fully reduced cytochrome oxidase with oxygen at room temperature', Chemica Scripta, 26(A), pp. 63-69. 
Otrin, L. et al. (2017) 'Towards Artificial Mitochondrion: Mimicking Oxidative Phosphorylation in Polymer and Hybrid Membranes', Nano Letters.

Parashar, A., Venkatachalam, A., et al. (2014) 'Cyanide does more to inhibit heme enzymes, than merely serving as an active-site ligand', Biochemical and Biophysical Research Communications, 455(3-4). doi: 10.1016/j.bbrc.2014.10.137.

Parashar, A., Gade, S. K., et al. (2014) 'The curious case of benzbromarone: Insight into superinhibition of cytochrome P450', PLOS ONE, 9(3). doi: 10.1371/journal.pone.0089967.

Parashar, A. and Manoj, K. M. (2012) 'Traces of certain drug molecules can enhance hemeenzyme catalytic outcomes', Biochemical and Biophysical Research Communications, 417(3). doi: 10.1016/j.bbrc.2011.12.090.

Picard, M. et al. (2011) 'Mitochondria: isolation, structure and function.', The Journal of physiology. England, 589(Pt 18), pp. 4413-4421. doi: 10.1113/jphysiol.2011.212712.

Prebble, J. N. (2001) 'The philosophical origins of Mitchell's chemiosmotic concepts', Journal of the History of Biology, 34(3), pp. 433-460.

Prebble, J. and Weber, B. (2003) Wandering in the Gardens of the Mind: Peter Mitchell and the Making of Glynn. Oxford University Press.

Quinlan, C. L. et al. (2012) 'Mitochondrial complex II can generate reactive oxygen species at high rates in both the forward and reverse reactions', Journal of Biological Chemistry, 287(32), pp. 27255-27264.

Racker, E. and Stoeckenius, W. (1974) 'Reconstitution of purple membrane vesicles catalyzing light-driven proton uptake and adenosine triphosphate formation', Journal of Biological Chemistry, 249(2), pp. 662-663.

Reid, R. A., Moyle, J. and Mitchell, P. (1966) 'Synthesis of adenosine triphosphate by a protonmotive force in rat liver mitochondria', Nature, 212, pp. 257-258.

Ristow, M. and Schmeisser, S. (2011) 'Extending life span by increasing oxidative stress', Free Radical Biology and Medicine, 51(2), pp. 327-336. doi: https://doi.org/10.1016/j.freeradbiomed.2011.05.010.

Sazanov, L. A. (2015) 'A giant molecular proton pump: structure and mechanism of respiratory complex I’, Nature Reviews: Molecular Cell Biology, 16(6), p. 375.

Schägger, H. and Pfeiffer, K. (2001) 'The ratio of oxidative phosphorylation complexes I-V in bovine heart mitochondria and the composition of respiratory chain supercomplexes', Journal of Biological Chemistry, 276(41), pp. 37861-37867.

Schwerzmann, K. et al. (1986) 'Molecular architecture of the inner membrane of mitochondria from rat liver: a combined biochemical and stereological study', The Journal of cell biology, 102(1), pp. 97-103. 
Slater, E. C. (1987) 'The mechanism of the conservation of energy of biological oxidations', FEBS Journal, 166(3), pp. 489-504.

Spudich, J. L. and Stoeckenius, W. (1980) 'Light-regulated retinal-dependent reversible phosphorylation of Halobacterium proteins', Journal of Biological Chemistry, 255(12), pp. 5501-5503.

Stadtman, E. R. and Levine, R. L. (2003) 'Free radical-mediated oxidation of free amino acids and amino acid residues in proteins', Amino Acids, 25(3-4), pp. 207-218.

Tokutake, N., Miyoshi, H. and Fujita, T. (1991) 'Electron transport inhibition of the cytochrome bc1 complex of rat-liver mitochondria by phenolic uncouplers', Biochimica et Biophysica Acta (BBA)-Bioenergetics, 1057(3), pp. 377-383.

Uchida, K. (2003) '4-Hydroxy-2-nonenal: a product and mediator of oxidative stress', Progress in Lipid Research, 42(4), pp. 318-343.

Venkatachalam, A., Parashar, A. and Manoj, K. M. (2016) 'Functioning of drug-metabolizing microsomal cytochrome P450s: In silico probing of proteins suggests that the distal heme "active site" pocket plays a relatively "passive role" in some enzyme-substrate interactions', In Silico Pharmacology, 4(1), p. 1. doi: 10.1186/s40203-016-0016-7.

Voet, D. and Voet, J. G. (2011) Biochemistry. 4th. Wiley, Hoboken, NJ, USA.

Wainio, W. W. (1985) 'An assessment of the chemiosmotic hypothesis of mitochondrial energy transduction', International Review of Cytology, 96, pp. 29-50.

Watling-Payne, A. S. and Selwyn, M. J. (1974) 'Inhibition and uncoupling of photophosphorylation in isolated chloroplasts by organotin, organomercury and diphenyleneiodonium compounds', Biochemical Journal, 142(1), pp. 65-74.

Watt, I. N. et al. (2010) 'Bioenergetic cost of making an adenosine triphosphate molecule in animal mitochondria', Proceedings of the National Academy of Sciences, 107(39), pp. 1682316827.

Way, J. L. (1984) 'Cyanide intoxication and its mechanism of antagonism', Annual Review of Pharmacology and Toxicology, 24(1), pp. 451-481.

Williams, R. J. P. (1979) 'Some unrealistic assumptions in the theory of chemi-osmosis and their consequences’, FEBS Letters, 102(1), pp. 126-132.

Wu, M. et al. (2016) 'Structure of Mammalian Respiratory Supercomplex I1III2IV1', Cell, 167(6), pp. 1598-1609. e10.

Zorov, D. B., Juhaszova, M. and Sollott, S. J. (2014) 'Mitochondrial Reactive Oxygen Species (ROS) and ROS-Induced ROS Release', Physiological Reviews, 94(3), pp. 909-950. doi: 10.1152/physrev.00026.2013. 